\title{
Mechanical Properties and Histology of Cortical Bone from Younger and Older Men'
}

\author{
F. GAYNOR EVANS \\ Department of Anatomy, The University of Michigan Medical School, \\ Ann Arbor, Michigan 48104
}

\begin{abstract}
Tensile breaking load, strength, strain, modulus of elasticity and density plus the histological structure at the fracture site, were determined for 207 standardized specimens of cortical bone from the embalmed femur, tibia, and fibula of 17 men from 36 to 75 years of age. The men were divided into a younger group ( 41.5 years old-avg) and an older group ( 71 years old-avg). Specimens from younger men had a greater average breaking load, strength, strain, modulus and density than those from older men. The percentage of spaces in the break area was greater in specimens from older men, but specimens from younger men had a slightly greater percentage of osteons, osteon fragments, and interstitial lamellae. The number of osteons $/ \mathrm{mm}^{2}$ and of osteon fragments $/ \mathrm{mm}^{2}$ was greater in specimens from older men but the average area/ osteon and area/osteon fragment was greater in specimens from younger men. Thus, there are quantitative and qualitative differences in the histological structure of bone from younger and older men. Differences in the tensile properties of bone from younger and older men can be explained by histological differences in the bone.
\end{abstract}

There is an extensive literature on age changes in the anatomy, physiology, biochemistry, mineralization, and pathology of human bone, considerably less on age changes in the mechanical properties of human bone, and least of all on the interrelations of age, mechanical properties and histology or biochemistry of human bone.

Uehira ('60) reported that both the compressive and the tensile strength of cortical bone from adult Japanese subjects declined with advancing age. The decline in the compressive strength was attributed to a decrease in the strength of the cement substance and the decline in the tensile strength was attributed to an increase in the cross sectional area of the Haversian canals.

According to Sugiyama ('60), the Rockwell hardness of Japanese cortical bone decreases with age. The decrease is caused by osteoporosis and not by changes in the calcium content of the bone.

Relations between osteoporosis and age variations in the compressive strength and trabecular density of fourth and fifth lumbar vertebrae, obtained at autopsy, of peo- ple 26 to 85 years of age were investigated by Bell et al. (' 67 ). Trabecular density of specimens from the iliac crest was designated as the "iliac crest score." Ultimate compressive strength and strain and the ash content per unit volume were the variables determined.

Failure strain was independent of vertebral size and strength but the relative ash content and the iliac crest score were closely correlated with each other. Ultimate strength and ash content decreased with age, the former more rapidly than the latter, but bone quality was apparently unchanged in osteoporosis.

Rockoff et al. ('69) determined the relative contribution of specimens of cortical and central trabecular bone, from lumbar vertebrae of people of various ages, to the peak non-destructive strength of the specimens. Cortical bone contributed 45-75\% of the peak strength of the specimens, regardless of the percent ash or the density

\footnotetext{
Received Aug. 25, '75. Accepted Nov. 28, '75.

1 This research was supported in part by Research Grant AM-03865 from the National Institutes of Health, Department of Health, Education, and Welfare.
} 
of the trabecular bone. Half of the load was supported by the trabecular bone if the ash content exceeded $59 \%$. Trabecular bone supported less load in people over 40 than in those under 40 years of age.

Dynamic mechanical properties of viable cortical bone, removed from the middle of the tibia of 8 patients immediately after operation, were investigated by Black and Korostoff ('73). They found that the tensile modulus of elasticity at $35.4 \mathrm{~Hz}$ declined with age but little or no such tendency occurred at $353.6 \mathrm{~Hz}$. At $35.4 \mathrm{~Hz}$ the modulus decreased with increasing inorganic content but at $353.6 \mathrm{~Hz}$ the modulus increased under the same inorganic content condition.

Wilson ('73) studied age changes in the compressive strength and bone mineral per unit volume of compact bone in specimens from 24 skeletons of individuals 35 to 89 years of age. According to him, after 35 years of age, the maximum compressive strength decreased about $7 \%$ and the bone mineral per unit volume about $3.3 \%$ per decade.

The present investigation on the interrelations of mechanical properties, density, age, percentage of various histological components in the cross sectional area, number of these components per unit area, and the size (area in square millimeters) of these components was undertaken in an attempt to explain age changes in the mechanical properties of adult human cortical bone.

\section{MATERIALS AND METHODS}

The present study was based upon 207 standardized test specimens of cortical bone from embalmed bodies of 17 men from 36 to 75 years of age. None of the men died from primary bone diseases. Test specimens were taken from the various thirds and quadrants of the femoral and tibial shaft but, because of its small size, only from the various thirds of the fibula. Embalmed material was used because it was impossible to obtain a suffcient number of intact, unembalmed bones so that test specimens could be obtained from all parts of the bones.

The men were divided into a younger group of eight men, with an average age of 41.5 years, and an older group, of nine men, with an average age of 71 years. A 9 -year interval separated the oldest and the youngest men of the younger and older group, respectively. Mechanical properties, density, and histological structure were determined for 35 femoral, 67 tibial, and 20 fibular specimens from the younger men and for 35 femoral, 34 tibial, and 16 fibular specimens from the older men.

Flat tensile specimens of compact bone were machined to a standardized size and shape with a \#1000 Unimat equipped with a $\# 1210$ milling table (fig. 1). The middle region of the specimen was reduced in order to concentrate the stress and strain in the region where they are measured. The dimensions of the reduced region of the specimen were standardized at 0.15 inches $(3.8 \mathrm{~mm}) \times 0.090$ inches $(2.3 \mathrm{~mm})$ giving a cross sectional area of $0.0135 \mathrm{in}^{2}$. $\left(8.74 \mathrm{~mm}^{2}\right)$. All dimensions of the specimens were standardized with a variation of \pm 0.01 inches.

Test specimens were kept moist at all times and great care was taken during their preparation to prevent drying or overheating. All mechanical property determinations were made on wet or moist specimens since drying is known to significantly affect mechanical properties of bone (Evans and Lebow, '51; Evans, '73).

Density of the specimens was deter-

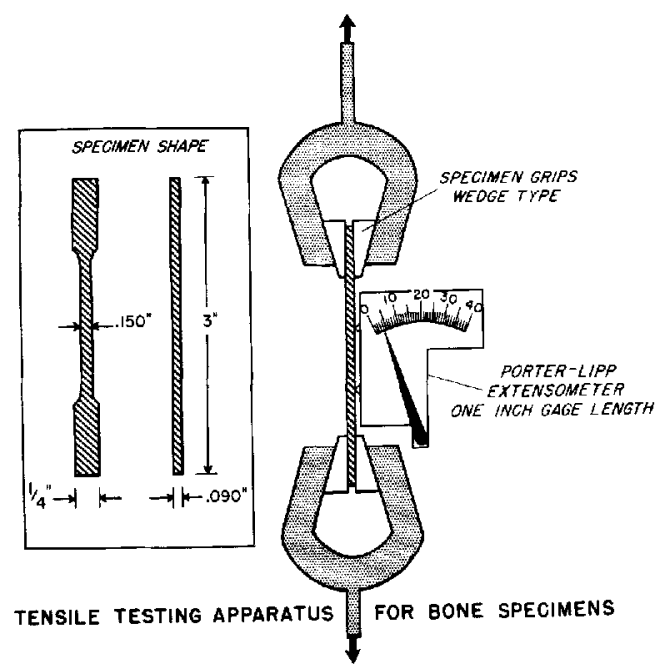

Fig. 1 From Evans and Lebow, 1951. 
mined with a densitometer developed by Evans et al. ('51). Dry specimens were used for these determinations in order to avoid the effect of moisture that may have been entrapped within the spaces in the specimen.

Tensile breaking load and the ultimate tensile strength of a specimen were determined by loading it to failure in a Riehle $5,000 \mathrm{lb}(2,267 \mathrm{~kg})$ capacity materials testing machine calibrated to an accuracy of $\pm 0.5 \%$. The specimen was loaded in the direction of its long axis, which coincided with that of the intact bone, at a constant rate of 0.045 inches/min (approximately $1.1 \mathrm{~mm} / \mathrm{min}$ ). The low range scale of the testing machine, $0-250 \mathrm{lbs}$ (0-90 kg), was used so that the load was recorded on the dial of the machine in units of $0.5 \mathrm{lbs}(0.45 \mathrm{~kg})$. During a test the specimen was held by wedge-shaped jaws especially designed for tensile testing so that the greater the tension on the specimen the tighter is the grip on it (fig. 1). Before starting a test care was taken to be certain that the specimen was perfectly aligned in the testing machine and jaws to ensure that the load would be uniformly distributed over the cross sectional area of the reduced region of the specimen where stress and strain were measured.

Tensile strain ( $\%$ elongation) occurring in a specimen during a test was measured with a Porter-Lipp mechanical extensometer attached to one edge of the reduced region of the specimen (fig. 1). The extensometer had a gauge length of 1 inch (25.4 mm) and was calibrated in units of 0.001 inches $(0.025 \mathrm{~mm})$. Failure of a specimen had to occur between the gauge marks to be a valid test.

From the stress and strain data obtained during a test a stress-strain curve (or diagram) was drawn (fig. 2). From this curve ultimate stress and strain as well as the proportional limit, modulus of elasticity, and energy the specimen absorbed to failure could be computed. The proportional limit is the limit up to which stress is directly proportional to strain. The modulus of elasticity, a measurement of the stiffness of the specimen (or material), was calculated on the basis of a tangent drawn to the straightest part of the stress-strain curve.
Tensile properties were the only mechanical properties of bone considered in the present investigation. The reason for this limitation is that clinical experience (Matti, '18) as well as experimental evidence obtained from studies with strain sensitive lacquers and strain gauges (Evans, '57) indicate that most fractures arise from failure of the bone from tensile stresses and strains within it caused by bending or torsion. During bending or torsion the surface of the bone is subjected to both tensile and compressive stresses and strain. Failure or fracture is initiated in the area of bone under tension because the tensile strength of bone is considerably less than its compressive strength. Because of the role of tension in fracture mechanics the tensile properties of bone are the most important ones to study. For additional information on tensile and compressive stress distribution in bending and torsion consult Harris ('63).

Cross sections of the reduced area of the specimens, taken as close as possible to the fracture site, were ground to a thickness of $75 \mu \mathrm{m}$, decalcified and photographed without staining in ordinary light with a Zeiss photomicroscope. Linear measurements of 20 undecalcified and 20 decalcified sections showed that decalcification reduced the dimensions of the section by $0.655 \%$, an insignificant amount.

The histological composition of the sec-

\section{STRESS - STRAIN \\ EMBALMED, WET TESTED FEMUR}

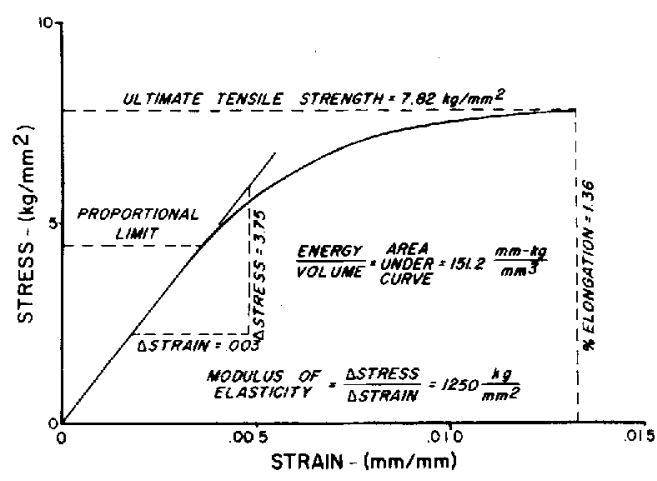

Fig. 2 Tensile stress-strain curve of a cortical bone specimen from the lateral quadrant of the distal third of the femur of a white man 66 years of age. (From Evans, '73.) 
tions was based on an analysis of prints of the photomicrographs which were enlarged to a standardized size on photographic paper of a known weight. Since the weight of a given area of the photographic paper was known it was possible to derive a conversion formula by means of which paper weight (grams) could be converted into area $\left(\mathrm{mm}^{2}\right)$.

The enlarged print was carefully cut out, weighed, and its area determined. This area represented the original break area (OBA) of the reduced region of the specimen as measured with vernier calipers at the time of testing. However, such measurements did not allow for irregularities in the margins of the cross section nor for spaces within the section. Therefore, all the major spaces (Haversian and Volkmann's canals, resorption spaces, etc.) within the cross section were cut out, weighed, and their area determined. This area was then subtracted from the original break area to determine the corrected break area (CBA) or net cross sectional area of the reduced region of the specimen.
The various histological components in the sections (fig. 3 ) were cut out, weighed, and the percentage of the corrected break area formed by each was calculated. Also determined were the number of each histological component per unit area as well as the cross sectional area per component. The basic assumption underlying this approach was that the specimen failed where it did because it was structurally weakest, as revealed by its histology, at the failure site. During the analysis of the photomicographs reference was frequently made to the original cross section.

The corrected break area (CBA) represents the area of bone actually subjected to stress during a test with the exception of the area of the lacunae and of the canaliculi which, according to Frost (60), together constitute $2.28 \%$ of vascular-free cortical bone volume in human long bones. Therefore, the exclusion of the area of the lacunae and the canaliculi probably has no significant effects on our results.

The histological data were then analyzed with respect to age changes in the per-

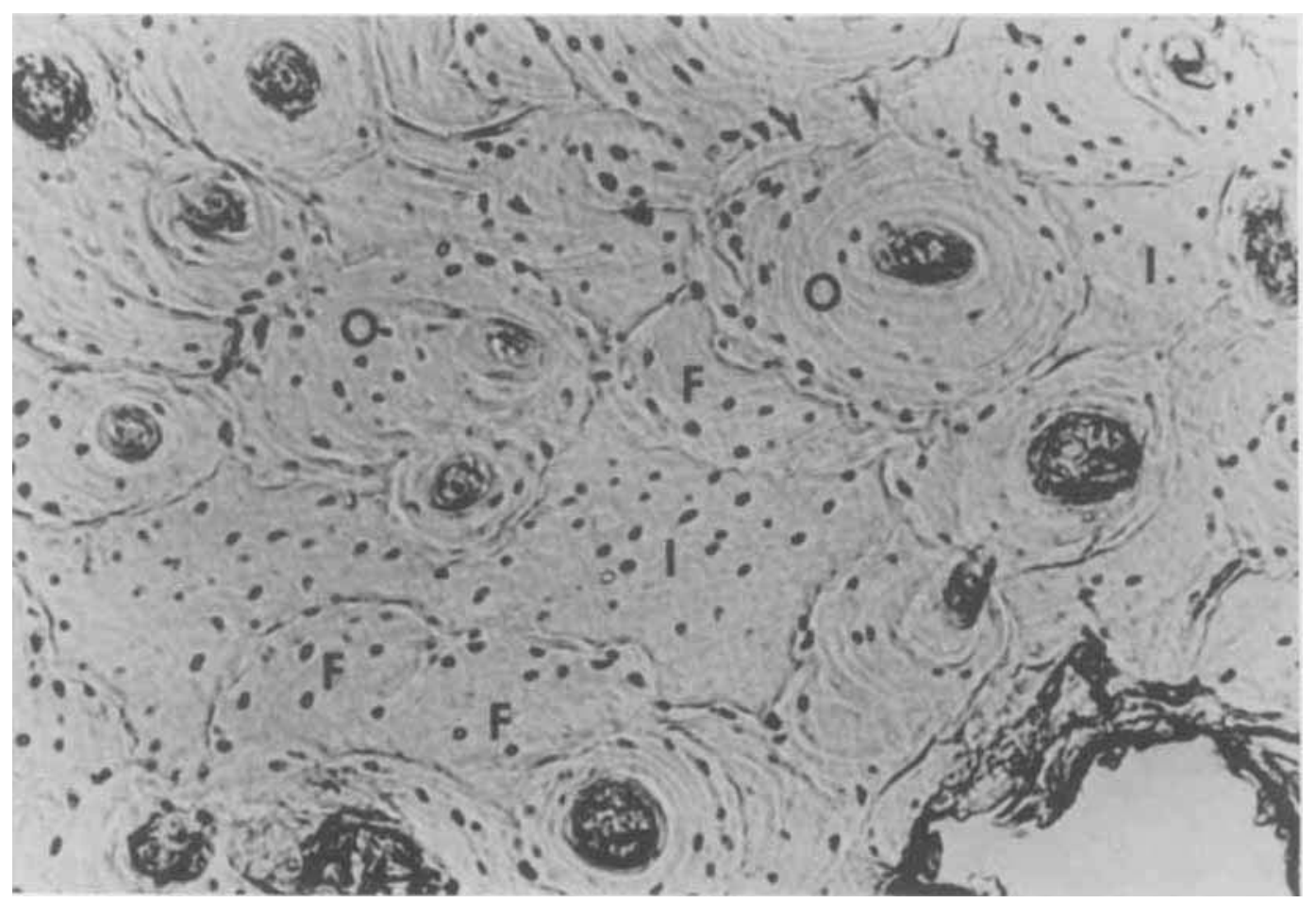

Fig. 3 Portion of a photomicrograph of a cross section of cortical bone from an adult man. F, fragment (remnant) of a secondary osteon; $I$, interstitial lamellae; $O$, secondary osteon. 
centage of the original break area formed by spaces, and the percentage of the corrected break area formed by secondary osteons, by fragments or remnants of secondary osteons, and by interstitial lamellae (fig. 3) interposed between definitive osteons and osteon fragments. The number of osteons $/ \mathrm{mm}^{2}$, the number of fragments of osteons $/ \mathrm{mm}^{2}$, the average cross sectional area $\left(\mathrm{mm}^{2}\right)$ per osteon and the average cross sectional area $\left(\mathrm{mm}^{2}\right)$ per osteon fragment were also calculated. Age changes in the histological data were then related to age changes in the mechanical properties and density of the specimens.

\section{RESULTS}

Comparison of the average mechanical property and density data for specimens from the individual bones (table 1) revealed that in the younger men tibial specimens had the highest breaking load, ultimate tensile strength, and density while fibular specimens had the highest tensile strain and modulus of elasticity. Fibular specimens also had the lowest breaking load and tensile strength but the femoral specimens exhibited the lowest tensile strain and modulus of elasticity. Femoral and fibular specimens were the least dense.

Among specimens from older men the tibial ones showed the highest average breaking load, ultimate tensile strength, tensile strain, and modulus of elasticity. Femoral specimens from the same age group had the lowest breaking load, ultimate tensile stress, tensile strain, and modulus of elasticity. Femoral specimens were the most dense and fibular ones the least dense.

Examination of the data in table 1 also shows that for each bone the average mechanical property and density values were greater in specimens from younger men than in those from older men.

Comparison of the average percentage of the original break area (OBA) formed by spaces and of the corrected break area (CBA) formed by various histological com-

TABLE 1

Average values for mechanical and physical properties of wet embalmed cortical bone from younger and older men.

\begin{tabular}{cccccccc}
\hline Bone & Agc & $\begin{array}{c}\text { No. } \\
\text { spec. }\end{array}$ & $\begin{array}{c}\text { Breaking } \\
\text { load } \\
(\mathrm{kg})\end{array}$ & $\begin{array}{c}\text { Ultimate } \\
\text { tensile } \\
\text { strength } \\
\left(\mathrm{kg} / \mathrm{mm}^{2}\right)\end{array}$ & $\begin{array}{c}\text { Tensile strain } \\
(\% \text { elongation })\end{array}$ & $\begin{array}{c}\text { Modulus of } \\
\text { elasticity } \\
\left(\mathrm{kg} / \mathrm{mm}^{2}\right)\end{array}$ & $\begin{array}{c}\text { Density } \\
\left(\mathrm{g} / \mathrm{cm}^{3}\right)\end{array}$ \\
\hline Femur & 41.5 & 35 & 71.2 & 10.2 & 1.32 & 1490 & 1.91 \\
& 71.0 & 35 & 57.2 & 6.8 & 1.07 & 1360 & 1.85 \\
Tibia & 41.5 & 67 & 83.0 & 10.6 & 1.76 & 1890 & 1.96 \\
& 72.0 & 34 & 70.8 & 8.4 & 1.56 & 1620 & 1.83 \\
Fibula & 33.0 & 20 & 64.9 & 10.0 & 2.10 & 1920 & 1.91 \\
& 59.0 & 16 & 57.6 & 8.0 & 1.19 & 1520 & 1.73 \\
\hline
\end{tabular}

$\mathrm{Kg} / \mathrm{mm}^{2}=$ kilogram force $/ \mathrm{sq}$. millimeter $\left(\mathrm{mm}^{2}\right)$

Kg $/ \mathrm{mm}^{2}=$ kilogram force $/ \mathrm{sq}$. millimeter $\left(\mathrm{mm}^{2}\right)$.
Kilogram force $/ \mathrm{mm}^{2} \times 9.806650 \times 10^{6}=$ Newtons $/ \mathrm{sq}$. meter $\left(\mathbf{N} / \mathrm{m}^{2}\right)$.

TABLE 2

Average percent of the break area of cortical bone formed by different histological components in younger and older men

\begin{tabular}{ccccccr}
\hline Bone & Age & $\begin{array}{c}\text { No. } \\
\text { spec. }\end{array}$ & $\begin{array}{c}\% \text { CBA formed by } \\
\text { osteons }\end{array}$ & $\begin{array}{c}\% \text { CBA formed by } \\
\text { osteon fragments }\end{array}$ & $\begin{array}{c}\% \text { CBA formed by } \\
\text { interst. lamellae }\end{array}$ & $\begin{array}{c}\% \text { OBA } 2 \text { formed } \\
\text { by spaces }\end{array}$ \\
\hline \multirow{2}{*}{ Femur } & 41.5 & 35 & 48.61 & 11.87 & 39.53 & 5.81 \\
& 71.0 & 35 & 43.78 & 11.74 & 44.21 & 15.02 \\
Tibia & 41.5 & 67 & 35.31 & 12.45 & 55.09 & 5.94 \\
& 72.0 & 34 & 40.03 & 8.89 & 51.09 & 10.80 \\
Fibula & 33.0 & 20 & 37.12 & 12.66 & 49.92 & 4.42 \\
& 59.0 & 16 & 37.05 & 13.40 & 45.72 & 6.16 \\
\hline
\end{tabular}

1 CBA, corrected break area (original break area minus spaces).

2 OBA, original break area. 
TABLE 3

Average number $/ \mathrm{mm}^{2}$ and area $\left(\mathrm{mm}^{2}\right)$ of various histological components of cortical bone. from younger and older men

\begin{tabular}{|c|c|c|c|c|c|c|}
\hline Bone & Age & $\begin{array}{l}\text { No. } \\
\text { spec. }\end{array}$ & $\begin{array}{c}\text { No. osteons } \\
/ \mathrm{mm}^{2}\end{array}$ & $\begin{array}{l}\text { No. osteon } \\
\text { frag. } / \mathrm{mm}^{2}\end{array}$ & $\begin{array}{c}\text { Avg. area } \\
\text { osteon }\left(\mathrm{mm}^{2}\right)\end{array}$ & $\begin{array}{c}\text { Avg. area/osteon } \\
\text { frag. }\left(\mathrm{mm}^{2}\right)\end{array}$ \\
\hline Femur & $\begin{array}{l}41.5 \\
71.0\end{array}$ & $\begin{array}{l}35 \\
35\end{array}$ & $\begin{array}{l}12.47 \\
14.76\end{array}$ & $\begin{array}{l}3.53 \\
4.73\end{array}$ & $\begin{array}{l}0.0410 \\
0.0276\end{array}$ & $\begin{array}{l}0.0349 \\
0.0244\end{array}$ \\
\hline Tibia & $\begin{array}{l}41.5 \\
72.0\end{array}$ & $\begin{array}{l}67 \\
34\end{array}$ & $\begin{array}{l}11.42 \\
15.39\end{array}$ & $\begin{array}{l}3.39 \\
4.40\end{array}$ & $\begin{array}{l}0.0314 \\
0.0261\end{array}$ & $\begin{array}{l}0.0269 \\
0.0206\end{array}$ \\
\hline Fibula & $\begin{array}{l}33.0 \\
59.0\end{array}$ & $\begin{array}{l}20 \\
16\end{array}$ & $\begin{array}{l}9.28 \\
9.96\end{array}$ & $\begin{array}{l}3.90 \\
4.08\end{array}$ & $\begin{array}{l}0.0409 \\
0.0354\end{array}$ & $\begin{array}{l}0.0344 \\
0.0339\end{array}$ \\
\hline
\end{tabular}

TABLE 4

Average values for mechanical properties and density of cortical bone from younger and older men

\begin{tabular}{|c|c|c|c|c|c|}
\hline & $\underset{(\mathrm{kg})}{\text { Breaking load }}$ & $\begin{array}{c}\text { Ultimate } \\
\text { tensile } \\
\text { strength } \\
\left(\mathrm{kg} / \mathrm{mm}^{2}\right)\end{array}$ & $\begin{array}{l}\text { Tensile strain } \\
(\% \text { elongation })\end{array}$ & $\begin{array}{c}\text { Modulus of } \\
\text { elasticity } \\
\left(\mathrm{kg} / \mathrm{mm}^{2}\right)\end{array}$ & $\begin{array}{l}\text { Density } \\
\left(\mathrm{g} / \mathrm{cm}^{-3}\right)\end{array}$ \\
\hline Younger & 73.03 & 10.27 & 1.73 & 1766 & 1.93 \\
\hline Older & 61.87 & 7.73 & 1.27 & 1500 & 1.80 \\
\hline
\end{tabular}

$\mathrm{Kg} / \mathrm{mm}^{2}=$ kilogram force $/ \mathrm{sq}$. millimeter $\left(\mathrm{mm}^{2}\right)$,

Kilogram force $/ \mathrm{mm}^{2} \times 9.806650 \times 10^{6}-$ Newtons $/$ sq. meter $\left(\mathrm{N} / \mathrm{m}^{2}\right)$.

ponents also revealed differences in the two age groups (table 2).

Among younger men the tibial specimens had the highest and the fibular specimens the lowest percentage of spaces. The highest and the lowest percentage of osteons in the corrected break area was found in the femoral and the tibial specimens, respectively. Fibular specimens had the highest and femoral ones the lowest percentage of osteon fragments in the corrected break area. Tibial and femoral specimens had the highest and lowest percentage, respectively, of interstitial lamellae in the corrected break area.

In specimens from older men the highest and lowest percentage of spaces in the original break area were found in the femoral and fibular specimens, respectively. These same specimens also had the highest and lowest percentage of osteons, respectively, in the corrected break area. The percentage of osteon fragments in the same break area was greatest and least, respectively, in the fibular and tibial specimens. The latter specimens had the largest and the femoral specimens the smallest percentage of interstitial lamellae in the corrected break area.

In each bone the percentage of spaces in the original break area was always greater in specimens from older men but such uniformity was not found with respect to the percentage of various histological components in the corrected break area.

Variations, according to the bone from which the specimens were obtained, were also found in the average number of osteons $/ \mathrm{mm}^{2}$, number of osteon fragments / $\mathrm{mm}^{z}$, area/osteon, and area/osteon fragment (table 3). In specimens from younger men femoral ones had the most and fibular ones the fewest osteons $/ \mathrm{mm}^{2}$. Fibular specimens had the most and tibial specimens the least osteon fragments/ $\mathrm{mm}^{2}$. The largest osteons and osteon fragments (area in $\mathrm{mm}^{2}$ ) were in the femoral specimens and the smallest in the tibial specimens.

Among specimens from older men the tibial ones had the most and the fibular ones the fewest osteons $/ \mathrm{mm}^{2}$. Femoral specimens had the most osteon fragments/ $\mathrm{mm}^{2}$ and fibular specimens the fewest. The largest osteons $\left(\mathrm{mm}^{2}\right)$ and osteon fragments $\left(\mathrm{mm}^{2}\right)$ were found in fibular specimens and the smallest in tibial ones.

In each bone the number of osteons/ $\mathrm{mm}^{2}$ and osteon fragments $/ \mathrm{mm}^{2}$ was greater in specimens from older men than in those from younger men. However, the 
TABLE 5

Average values for histological components in cortical bone of younger and older men

\begin{tabular}{lcccc}
\hline & CBA ${ }^{1}$ osteons & $\begin{array}{c}\text { \% CBA osteon } \\
\text { fragments }\end{array}$ & $\begin{array}{c}\text { \% CBA inter- } \\
\text { stitial lamellae }\end{array}$ & $\%_{\text {OB }}$ OB spaces \\
\hline Younger & 40.35 & 12.33 & 48.18 & 5.39 \\
Older & 40.29 & 11.34 & 47.01 & 10.66 \\
\hline
\end{tabular}

1 CBA, corrected break area (original break area minus spaces).

OBA, original break area.

TABLE 6

Average number/unit area and size of histological components in cortical bone from younger and older men

\begin{tabular}{lcccc}
\hline & $\begin{array}{c}\text { No. osteons } \\
\text { mm² }^{2}\end{array}$ & $\begin{array}{c}\text { No. osteon fragments } \\
\text { mm }^{2}\end{array}$ & $\begin{array}{c}\text { Avg.area/osteon } \\
\left(\mathrm{mm}^{2}\right)\end{array}$ & $\begin{array}{c}\text { Avg. area/osteon } \\
\text { fragments (mm }\end{array}$ \\
\hline Younger & 11.06 & 3.61 & 0.04 & 0.032. \\
Older & 13.37 & 4.40 & 0.03 & 0.026 \\
\hline
\end{tabular}

osteons and osteon fragments were larger in specimens from younger men than in those from older men.

Since the primary interest of the present investigation was a determination of differences in the mechanical properties, density, and histological structure of cortical bone from younger and older men, the data were reanalyzed according to age group regardless of the bone from which the specimens came.

Differences between bone from younger and older men was further emphasized by this re-analysis. Thus, it was clearly shown that bone from younger men had a greater average tensile breaking load, ultimate tensile strength, tensile strain, modulus of elasticity, and density than bone from older men (table 4 ).

Comparison of the percentage of the break area formed by spaces and by various histological components also revealed differences between specimens from the two age groups. In specimens from older men the percentage of spaces in the original break area was almost twice as great as that in younger men (table 5 ). Since the cross sectional area of the reduced region of all the specimens was standardized at $0.0135 \mathrm{in}^{2}\left(8.75 \mathrm{~mm}^{2}\right)$ the greater percentage of spaces in specimens from older men means that their corrected break area, i.e., the area of bone actually subjected to force or load during a test, was only about half as great as that in specimens from younger men. Consequently, the fact that the per- cent of osteons, osteon fragments, and interstitial lamellae in older men was only a little less than that in younger men implies that bone from older men has smaller osteons and fragments than that from younger men.

The validity of this implication was evident when the number of osteons $/ \mathrm{mm}^{2}$ and of osteon fragments $/ \mathrm{mm}^{2}$ as well as the size $\left(\mathrm{mm}^{2}\right)$ per osteon and osteon fragment in specimens from younger and older men were compared (table 6). Specimens from older men had more osteons / $\mathrm{mm}^{2}$ and osteon fragments $/ \mathrm{mm}^{2}$ than specimens from younger men but the size of the osteons and osteon fragments was smaller in older men.

\section{DISCUSSION}

Since the present study is based upon embalmed bone the question arises as to what effect embalming has upon bone. There appears to be no valid reason for believing that embalming would quantitatively affect the histological elements studied in this investigation but the same is not true for the mechanical properties of bone. For obvious reasons it would be very difficult or impossible, in the case of human bone, to determine the tensile properties of bone in living animals.

Black and Korostoff ( 73 ) investigated the mechanical properties of viable human compact bone under dynamic cyclic loading. However, modulus of elasticity was the only mechanical property that could 
be determined with their method and they only tested eight specimens. Data given by Evans ('73) for the tensile properties of more than 200 specimens, equally divided between embalmed and unembalmed, of human compact bone showed that embalming increased the ultimate tensile strength by $9.95 \%$ and the modulus of elasticity by $1.63 \%$. However, tensile strain (\% elongation) was decreased $2.06 \%$ by embalming.

Data obtained in the present investigation clearly demonstrate that bone from younger and from older men differs not only in its tensile properties and density but also in its microscopic structure at the fracture site. The microscopic differences are both quantitative (less bone in the fracture site of older men ) as well as qualitative (smaller and more osteons $\mathrm{mm}^{2}$ in older men). The differences in the microscopic structure of bone from younger and older men may help in explaining the differences in the tensile properties of specimens from the two age groups because several investigators have noted a correlation between the mechanical properties of cortical bone and its microscopic structure (see reviews by Currey, '70; Evans, '57, '73; and Reilly and Burstein, '74).

Evans ('58) reported that the ultimate tensile strength of his specimens of adult human fibular bone, which had relatively few large osteons and their fragments, was greater than that of similar specimens of femoral bone, which had many small osteons and their fragments. He concluded that a few large osteons and their fragments increase the ultimate tensile strength of a given amount of cortical bone while an abundance of cement lines per unit area, such as occurs with many (100 or more) osteons and their fragments, reduces the tensile strength of bone.

This research was continued by Evans and Bang ('66) who found that the average percentage of the break area formed by spaces and by osteons was significantly greater $(1 \%)$ in specimens of adult human femoral bone than in fibular bone. Femoral bone had significantly $(1 \%)$ more osteons $/ \mathrm{mm}^{2}$ than fibular bone but the latter had significantly ( $1 \%$ ) more interstitial lamellae. Positive correlations
( $1 \%$ level) were found between tensile strain and the percent of osteons in the break area and equally high negative cor. relations between tensile strain and the number of osteons $/ \mathrm{mm}^{2}$ and between a single shearing strength and the area $\left(\mathrm{mm}^{2}\right) /$ osteon fragments. Tensile strain had a high negative correlation ( $2 \%$ level) with the percent of spaces in the break area.

Later Evans and Bang ('67) expanded their investigations by including tibial bone. Again differences were found in the percentage of the break area formed by osteons and by intersitial lamellae in specimens from the various bones. Femoral specimens had the highest percentage of osteons and of osteon fragments but the lowest percentage of interstitial lamellae in the break area. Tibial specimens had $1 \%$ more osteons and $4 \%$ more interstitial lamellae in the break area than did the fibular specimens. However, the latter had $2 \%$ more osteon fragments. Femoral specimens had the most osteons $/ \mathrm{mm}^{2}$ but the fibular specimens had the largest osteons.

A positive correlation, significant at the $2 \%$ level, was found between ultimate tensile strength and the percentage of interstitial lamellae in the break area while a negative correlation, at the $1 \%$ significance level, occurred between tensile strength and the percentage of osteons in the break area. An equally significant negative correlation was found between the tangent modulus of elasticity of the specimens and the percentage of spaces in the break area.

Currey ('59) also found a strong negative correlation between the number of osteons (Haversian systems), due to the amount of reconstruction, and the tensile strength of bovine bone. The reasons for his results advanced by Currey were (1) immature osteons have large Haversian canals which reduce the amount of bone, and (2) newly formed osteons are not completely mineralized and consequently are weaker than adjacent primary bone.

From their data Evans and Bang concluded that osteons tend to reduce the tensile strength and elastic modulus of bone while interstitial lamellae tend to increase them. According to them, the probable reason that osteons and their fragments tend 
to reduce the tensile strength of cortical bone is that they are surrounded by cement lines, which are sites of weakness. Thus, the more osteons and their fragments per unit area of bone the more cement lines there are where failure can occur.

The idea that cement lines are sites of weakness and failure was demonstrated in a decalcified cross section of cortical bone, from the unembalmed fibula of a 56-year-old Caucasian man, which was accidentally factured during mounting on a slide (fig, 4). The separation in the section occurred at the cement lines which indicates that they are areas of weakness. Evans and Bang ('66) noted a similar phenomenon in a decalcified cross section of an adult human femur that had accidentally dried after mounting. Tensile stresses produced during drying caused separations of the section at the cement lines.

Others have also noted that the cement lines appear to be weak areas. Maj and Toajari ('37) reported that the cohesiveness of the interfibrillar calcified substance is at least six times less than that of the collagen fibers and that in decalcified bone the Haversian systems (osteons) represent sites of greater resistance to fracture. Thus, when a fracture line imposes on them from a radial direction it follows the cement lines. This behavior was not found in undecalcified bone.

The mechanical significance of the histological components of fresh wet undecalcified cortical bone from the femur of a 32-year-old man and from a cow was investigated by Okamota ('55) who reported the cement lines have an important relation to both tension and compression, especially the latter.

In fresh undecalcified human long bones Aoji ('59) noted that lamellar separations during compression occurred at the interstitial part while in tension they occurred at the boundary of Haversian systems (osteons) and interstitial lamellae.

Dempster and Coleman ('61) determined the tensile strength, along and across the grain, of standardized undecalcified specimens of adult human tibial and mandibular bone. Four types of specimens, wet and dry, were tested in direct tension or in bending. Microradiographs of their specimens did not show any clear evidence that highly calcified areas are either more or less resistant to tensile or bending forces. In transverse sections the fracture line tended to follow the curvature of the cement lines around the osteons (Haversian systems), then veered across interstitial bone until it reached the cement line of an adjacent osteon. They concluded that the cement lines and the interlamellar

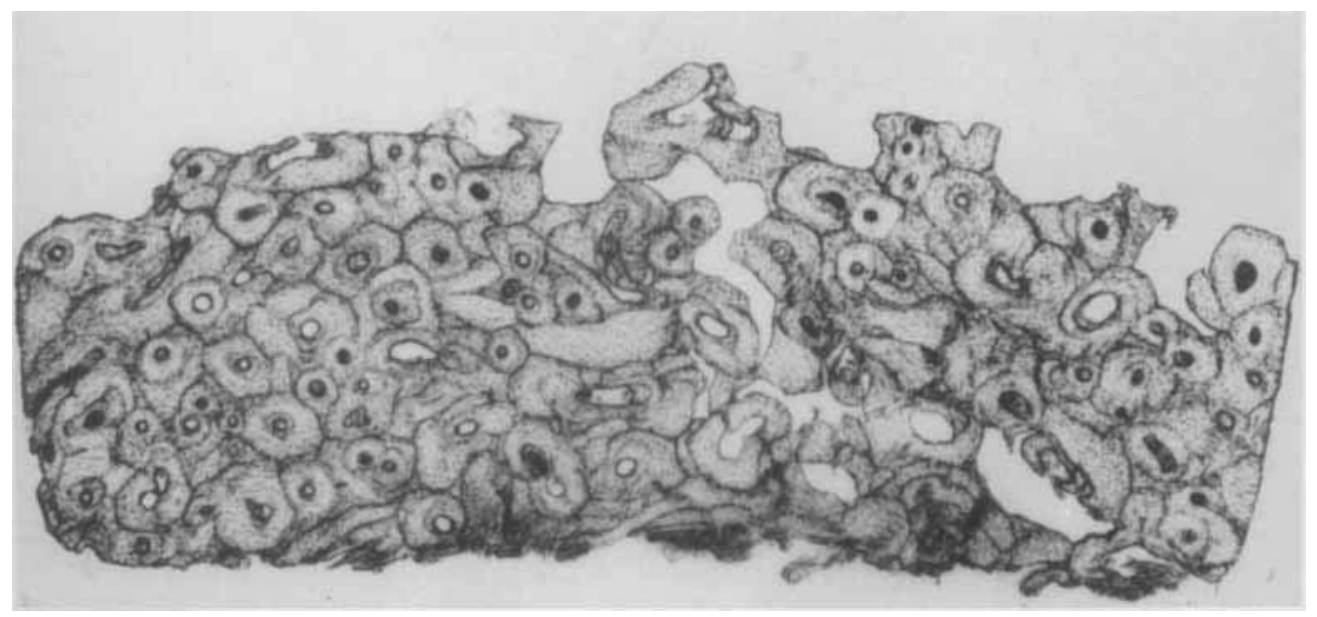

Fig. 4 Cross section, at the fracture site, of a decalcified specimen of cortical bone from the unembalmed fibula of a 56-year-old Caucasian man. Fracture of the section accidentally occurred while mounting it on a slide. Note tendency of the fracture to occur along cement lines. 
planes of osteons are the weaker structure elements.

Thus, evidence from several investigators indicates the cement lines are relatively weak areas where failure can be initiated. This appears to be true for decalcified or undecalcified, embalmed or fresh bone.

Osteons, primarily because of the Haversian canals, contribute to the porosity of bone. Furthermore, according to Aoji ('59), the size (area in $\mathrm{mm}^{2}$ ) of the Haversian canals in the femur of Japanese subjects 40 to 60 years of age was 1.19 times larger and in people over 60 years old 1.30 times larger than that of people 20 to 39 years of age. However, Currey ('64) did not find that the size of Haversian canals increased with age, and Singh and Gunberg ('70), who estimated age of men on the basis of bone fragments, reported that Haversian canal diameter decreased with age. Singh and Gunberg's data was obtained from mandibles, femurs or tibias of 40 male and mandible only of 19 male dissecting room cadavers.

Haversian canal size was not measured in our investigation but during analysis of the cross sections no marked increase in size of the Haversian canals was noticed in the specimens from older men. Perhaps the increase in size of the Haversian canal with age reported by Aoji is a racial characteristic of Japanese people. Although not specifically stated, Currey's material was probably Caucasian and Singh and Gunberg's Caucasian and/or Negro as is true for most dissecting room cadavers in the United States. Regardless of the size of the Haversian canals the increase in the number of osteons $/ \mathrm{mm}^{2}$, and hence the number of Haversian canals, in the specimens from the older men would increase their porosity (table 5) and reduce their density (table 4) in comparison with those of younger men.

Any holes or discontinuities in a material weaken it and create the possibilities of microfractures because of the stress concentration around the holes. The stress concentration is less if the holes are round than if they are square or rectangular because the stress concentration is highest at each corner of the square or rectangle.
Consequently, microfractures are most apt to be initiated at the corners of rectangular holes. In fact, if the cuts made when taking a bone graft for surgical transplantation cross one another, a site of high stress concentration is created at the point of crossing and the bone from which the graft is taken may fracture at that point.

Bone is full of holes or discontinuities - e.g. Haversian canals, lacunae, canaliculi, Volkmann's canals, and resorption areas. However, few, if any of these discontinuities have sharp corners, although all of them may create areas of higher stress concentration at which microfractures can occur.

The greater number of osteons $/ \mathrm{mm}^{2}$ in the specimens from older men means that there are more Haversian canals $/ \mathrm{mm}^{2}$ or areas of higher stress concentration. The lacunae and canaliculi also are sites of stress concentration where microfractures can be initiated. Currey (' 62 ) suggests (1) that the various orientations and shape of the lacunae reduces their stress concentrating effects to a minimum, and (2) their deleterious effects are compensated for by the tendency of the lacunae to stop the propagation of microfractures. However, Currey was working with whole cross sections of intact bones. In our small specimens the stress concentrating effects of the Haversian canals and lacunae, as sites for the initiation of microfractures, might be greater, relatively, than they would be in an intact bone.

Porosity may be a more important factor in the strength of bone than its density. For example, Evans and Bang ('67) found statistically significant differences in the mean density of 405 femoral, 183 tibial, and 37 fibular specimens of adult human cortical bone but an analysis of variance between the means revealed no statistically significant correlations between density and the tensile strength, tensile strain, modulus of elasticity, and Rockwell hardness of the specimens. These results suggest that the structure of bone, i.e., the way it is distributed per unit area, had a greater influence on its tensile properties and hardness than its density or the mere amount of bone per unit volume. This idea is supported by the results of the present 
study on differences between the tensile properties and microscopic structure of cortical bone from younger and older men.

\section{LITERATURE CITED}

Aoji, O. 1959 Metrical studies on the lamellar structure of human long bones. J. Kyoto Prefect. Med. Univ., 65: 941-965. (Japanese text, English summary).

Bell, G. H., O. Dunbar and J. S. Beck 1967 Variations in strength of vertebrae with age and their relation to osteoporosis. Calcif. Tissue Res., 1: 75-86.

Black, J., and E. Korostoff 1973 Dynamic mechanical properties of viable human cortical bone. J. Biomech., 6: 435-438.

Currey, J. D. 1959 Differences in the tensile strength of bone of different histological types. J. Anat., 93: 87-95.

1962 Stress concentrations in bone. Quart. J. Micr. Sci., 103: 111-133.

1964 Some effects of ageing in human Haversian systems. J. Anat., 98; 68-75.

1970 The mechanical properties of bone. Clin. Orthop., 73: 210-231.

Dempster, W. T., and R. F. Coleman 1961 Tensile strength of bone along and across the grain. J. Appl. Physiol., 16: 355-360.

Evans, F. G. 1957 Stress and Strain in Bones. C. C Thomas, Springfield, pp. 205-219.

1958 Relations between the microscopic structure and tensile strength of human bone. Acta Anat., 35: 285-301.

1973 Mechanical Properties of Bone. C. C Thomas, Springfield, pp. 282-310.

Evans, F. G., and S. Bang 1966 Physical and histological differences between human fibular and femoral compact bone. In: Studies on the Anatomy and Function of Bone and Joints, F. G. Evans, ed., Springer-Verlag, Heidelberg, pp. $142-155$.

1967 Differences and relationships between the physical properties and the microscopic structure of human femoral, tibial, and fibular cortical bone. Am. J, Anat,, 120: 79-88.
Evans, F. G., C. C. Coolbaugh and M. Lebow 1951 An apparatus for determining bone density by means of radioactive strontium $\left(\mathrm{Sr}^{90}\right)$. Science, 114: 182-185.

Evans, F. G., and M. Lebow 1951 Regional differences in some of the physical properties of the human femur. J. Appl. Physiol., 3: $563-572$.

Frost, H. M. 1960 Measurement of osteocytes per unit volume and volume components of osteocytes and canaliculae in man. Henry Ford Hosp. Med. Bull, 8 (no. 2, pt II): 208-211.

Harris, C. O. 1963 Strength of Materials. American Technical Society, Chicago.

Maj, G., and E. Toajari 1937 Osservazioni sperimentali sul meccanismo di resistenza del terruto osseo lamellare compatto alle azioni meccaniche. Chir. Organi Mov., 22: 541-557.

Matti, H. 1918 Die Knochenbrüche und ihre Behandlung. I. Band. Springer, Berlin.

Okamoto, T. 1955 Mechanical significance of components of bone-tissue. J. Kyoto Prefect. Med. Univ., 58: 1004-1006. (Japanese text, English summary).

Reilly, D. T., and A. H. Burstein 1974 The mechanical properties of cortical bone. J. Bone Jt. Surg., 56-A: 1001-1022.

Rockoff, S. D., E. Sweet and J. Bleustein 1969 The relative contribution of trabecular and cortical bone to the strength of human lumbar vertebrae. Calcif. Tissue Res., 3: 163-175.

Singh, I. J., and D. L. Gunberg 1970 Estimation of age at death in human males from quantitative histology of bone fragments. Am. J. Phys. Anthrop., 33 (N.S.): 373-381.

Sugiyama, Y, 1960 A study on the hardness of human bones. J. Kyoto Prefect. Med. Univ., 68: 557-569. (Japanese text, English summary).

Uehira, T. 1960 On the relation between the chemical components and the strength of the compact bone. J. Kyoto Prefect. Med. Univ., 68: 923-940. (Japanese text, English summary).

Wilson, C. R. 1973 Age related changes in the compressive strength and bone mineral per unit volume of compact bone. Phys. Med. Biol., 18: 587. (Abstract, Proc. Amer. Ass. Physcists in Med.) 